\title{
A New Alternative Synthesis of Salicylaldazine via Microwave Irradiation Method
}

\author{
Karimah Kassim (D), ${ }^{1}$ Muhamad Azwan Hamali ${ }^{(D)}{ }^{2}$ and Bohari Yamin ${ }^{3}$ \\ ${ }^{1}$ Institute of Science, Universiti Teknologi MARA, 40450 Shah Alam, Malaysia \\ ${ }^{2}$ Faculty of Applied Sciences, Universiti Teknologi MARA, 40450 Shah Alam, Malaysia \\ ${ }^{3}$ Faculty of Science and Technology, Universiti Sains Islam Malaysia, 71800 Nilai, Malaysia \\ Correspondence should be addressed to Karimah Kassim; karimah@salam.uitm.edu.my
}

Received 14 January 2019; Accepted 6 March 2019; Published 13 May 2019

Academic Editor: Liviu Mitu

Copyright (c) 2019 Karimah Kassim et al. This is an open access article distributed under the Creative Commons Attribution License, which permits unrestricted use, distribution, and reproduction in any medium, provided the original work is properly cited.

\begin{abstract}
Two diazine Schiff base ligands, HLa and HLb, derived from thiocarbohydrazide and salicylaldehyde derivatives were synthesized using the microwave-assisted synthesis approach. The confirmation of both ligands was elucidated through physiochemical and spectroscopy techniques as well as single $\mathrm{X}$-ray crystallography diffraction. The analyses showed that the ligands synthesized were formed as azine instead of thiocarbohydrazone based on the missing thione, $\mathrm{C}=\mathrm{S}$ moiety, throughout FTIR and NMR spectrascopic data. This finding was further concluded by X-ray crystal analysis. The biological properties of these ligands were screened using the disc diffusion method. The result shows that HLb shows significant inhibition towards all of the bacteria tested.
\end{abstract}

\section{Introduction}

Schiff bases, compounds derived from the condensation reaction of primary amine with carbonyl compounds are considered as "privileged ligand" by many due to its stability and structural design [1]. The azomethine $(\mathrm{C}=\mathrm{N})$ group found in Schiff base compounds is known to be biologically active. Thus, it received significant attention in chemistry and biology for its various properties such as antitumor [2], anti-inflammatory [3], and antimicrobial $[4,5]$.

The usage of microwave irradiation as nonconventional energy source in synthesizing organic and inorganic compounds has received interesting attention among the researchers due to the clean, convenient, and cost-effective method [6]. The heating up using microwave irradiation by "in-core" heating not only shortens the reaction time but also enhances product yield as well as enhances the purity by reducing unnecessary side reaction $[7,8]$.

A previous work [9] uses the two-step method in synthesizing salicylaldehyde azine Schiff base by obtaining a thiocarbohydrazone as intermediate before adding pyridine as catalyst to form azine. In this paper, a similar salicylaldehyde azine was resynthesized using the new alternative method through microwave irradiation. This method offers a new shorter route without obtaining an intermediate compound producing higher $\%$ yield. The structures were elucidated using physical and spectroscopy analyses and screened for biological activities.

\section{Materials and Methods}

2.1. General. All chemicals and reagents used in this synthesis work were commercially purchased from Sigma-Aldrich and Merck and of the analytical reagent (AR) grade. The solvents for the synthesis were used without further purification. The reactions were carried out using Anton Paar Monowave 450 in $\mathrm{G} 30$ boron silicate vials. Elemental microanalysis $(\mathrm{C}, \mathrm{H}$, and N) of the ligands was performed on a Thermo Flash EA 110 Elemental Analyzer. Melting points were measured with a Stuart Melting Point SMP10. The IR spectra were recorded using $\mathrm{KBr}$ discs in the range of $4000-400 \mathrm{~cm}^{-1}$ using a PerkinElmer FT-IR 1600 spectrophotometer ${ }^{1} \mathrm{H}$ and ${ }^{13} \mathrm{C}$ NMR spectra were recorded on Bruker Avance $300 \mathrm{MHz}$, and the samples were dissolved in DMSO- $\mathrm{d}^{6}$ solvent. 
2.2. Preparation of $2,2^{\prime}-\{[(E, E)$-Hydrazine-1,2-diylidene $]$ bis(methanylidene)\}diphenol (HLa). The ligand was synthesized as shown in Figure 1. A solution of thiocarbohydrazide $(2.5 \mathrm{mmol}, 0.27 \mathrm{~g}$ ) in $5 \mathrm{~mL}$ of $80 \%$ ethanol was added to an ethanolic solution of salicylaldehyde ( $5 \mathrm{mmol}, 0.61 \mathrm{~g}$ ). The mixture was then irradiated in the microwave for 5 minutes at $160^{\circ} \mathrm{C}$. A clear yellowish solution was obtained, and yellow microcrystalline was formed upon cooling. The microcrystalline was separated from the solvent through filtration and washed with cold ethanol and diethyl ether. Yield: $82 \%$; m.p.: $224-228^{\circ} \mathrm{C}$; anal. calcd for $\mathrm{C}_{14} \mathrm{H}_{14} \mathrm{~N}_{2} \mathrm{O}_{2}$ (\%): C, 70.85; H, 5.55; N, 11.02; found: C, 69.93; H, 4.80; N, 10.00; IR $\left(\lambda \operatorname{max~cm}{ }^{-1}\right)(\mathrm{KBr}): 2971(\mathrm{OH}), 1619(\mathrm{C}=\mathrm{N}), 1524$ $(\mathrm{C}=\mathrm{C}), 1322$ (C-O phenolic), $969(\mathrm{~N}-\mathrm{N}) ;{ }^{1} \mathrm{H}$ NMR $\delta(\mathrm{ppm})$ : 11.14 (s, 2H, phenolic $\mathrm{OH}), 9.02(\mathrm{~s}, 2 \mathrm{H}, \mathrm{HC}=\mathrm{N}), 7.71-6.96$ (m, 6H, aromatic).

2.3. Preparation of 5,5'-Dimethoxy-2,2'-\{[(E,E)-hydrazine1,2-diylidene]bis(methanylidene)\}diphenol (HLb). To a $5 \mathrm{~mL}$ ethanolic solution of 5-methoxysalicylaldehyde ( $5 \mathrm{mmol}, 0.27 \mathrm{~g})$, thiocarbohydrazide $(0.25 \mathrm{mmol}, 0.76 \mathrm{~g})$ in $5 \mathrm{~mL}$ of $80 \%$ ethanol was added before placing the mixture in the microwave reactor. The mixture was irradiated at $160^{\circ} \mathrm{C}$ for 5 minutes. A resultant bright yellow microcrystalline was obtained. The microcrystalline product was filtered and rinsed with cold ethanol and diethyl ether. Yield: 95\%; m.p.: $218-224^{\circ} \mathrm{C}$; anal. calcd for $\mathrm{C}_{16} \mathrm{H}_{16} \mathrm{~N}_{2} \mathrm{O}_{4}$ (\%): C, 63.99; $\mathrm{H}$, 5.37; N, 9.33; found: C, 62.95; H, 5.28; N, 8.88; IR ( $\lambda$ max $\left.\mathrm{cm}^{-1}\right)(\mathrm{KBr}): 3141(\mathrm{OH}), 2939\left(\mathrm{CH}_{3}\right), 1606(\mathrm{C}=\mathrm{N}), 1577$ $(\mathrm{C}=\mathrm{C}), 1322$ (C-O phenolic), $940(\mathrm{~N}-\mathrm{N}) ;{ }^{1} \mathrm{H}$ NMR $\delta(\mathrm{ppm})$ : 10.60 (s, 2H, phenolic $\mathrm{OH}), 8.96(\mathrm{~s}, 2 \mathrm{H}, \mathrm{HC}=\mathrm{N}), 7.29-6.91$ (m, 6H, aromatic), $2.95\left(\mathrm{~s}, 6 \mathrm{H}, \mathrm{CH}_{3}\right)$.

2.4. Antibacterial Study. Antibacterial test of pathogens was carried out by using the disc diffusion method according to [10]. The bacteria from stock culture were lightly inoculated into the Mueller Hinton Broth (MHB) and let to grow overnight at $37^{\circ} \mathrm{C}$ in an ambient air incubator. The culture was diluted with new MHB in order to achieve an optical density of 0.1 at wavelength of $625 \mathrm{~nm}$ in the spectrophotometer. Later, a sterile cotton swab was dipped into the broth culture and inoculated on the Mueller Hinton Agar (MHA). A $200 \mu \mathrm{g} / \mathrm{mL}$ of synthesized compounds was individually dissolved in DMSO before impregnating on a sterile Whatman $6 \mathrm{~mm}$ diameter disc and placed onto the surface of the agar containing the tested bacteria. The agar plate was incubated at $37^{\circ} \mathrm{C}$ for overnight. For each bacteria plate, gentamicin was used as positive control, while DMSO acted as negative control. The inhibition zone on the plate was recorded and measured in diameter $(\mathrm{mm})$.

\section{Results and Discussion}

The percentages of elemental analysis of both ligands are closely similar to the theoretical values. Both ligands have a low melting point range (within $6-8^{\circ} \mathrm{C}$ ), suggesting that the purity of the synthesized compound is high.
3.1. Infrared Spectroscopy. The experimental IR spectra for both ligands shown in Figure 2 exhibited strong absorptions around $1619-1606 \mathrm{~cm}^{-1}, 1577-1524 \mathrm{~cm}^{-1}$, and $1322-1318$ $\mathrm{cm}^{-1}$, which are attributed to the azomethine $(\mathrm{C}=\mathrm{N})$, aromatic benzene $(\mathrm{C}=\mathrm{C})$, and phenolic oxygen $(\mathrm{C}-\mathrm{O})$ functional groups, respectively. A sharp and strong peak found at $3291 \mathrm{~cm}^{-1}$ in the HLb spectra was designated to the C-H of the methoxy group $\left(\mathrm{O}-\mathrm{CH}_{3}\right)$. The weak and broad peak of hydroxyl $(\mathrm{OH})$ indicated the presence of intermolecular hydrogen bond formed between phenolic hydrogen with azomethine nitrogen $(\mathrm{OH} \cdots \mathrm{N}=\mathrm{C})$. In an earlier work, Chee et al. [5] synthesized a thiocarbohydrazone by reaction of similar amine with ketone instead of aldehyde. The infrared spectra of the thiocarbohydrazone shows a peak at $1232 \mathrm{~cm}^{-1}$, signifying the presence of thione $(C=S)$ in the ligand. This peak was found to be absent in both HLa and HLb spectra, and it was concluded that the $\mathrm{C}=\mathrm{S}$ was decomposed during the synthesis of azine ligands.

3.2. ${ }^{1} \mathrm{H}$ and ${ }^{13} \mathrm{C} N M R$. The ${ }^{1} \mathrm{H}$ and ${ }^{13} \mathrm{C}$ NMR spectra of $\mathrm{HLa}$ and HLb were recorded in DMSO- $\mathrm{d}^{6}$. In ${ }^{1} \mathrm{H} \mathrm{NMR}$, the-OH appeared as singlet at $11.14 \mathrm{ppm}$ and $10.60 \mathrm{ppm}$ for HLa and HLb, respectively. The formation of intermolecular hydrogen bonding between hydroxyl proton and the azomethine nitrogen causes the signal to appear at the downfield region as well as the deshielding effect of oxygen [11]. The singlet azomethine proton, $\mathrm{HC}=\mathrm{N}$ of $\mathrm{HLa}$ and $\mathrm{HLb}$, was found at $9.02 \mathrm{ppm}$ and $8.96 \mathrm{ppm}$, respectively. The chemical shift of aromatic benzene of both ligands appeared as multiplets in the vicinity of 7.71-6.69 ppm for HLa and 7.29-6.91 ppm for HLb. The proton benzene in HLb experienced a shielding due to the substituent effect caused by the presence of the methoxy group $-\mathrm{OCH}_{3}$. The methoxy group is an electrondonating group which adds electron density to the aromatic $\pi$-system, causing it to be more nucleophilic. The peak of methoxy protons of HLb can be found at the upperfield region of $3.37 \mathrm{ppm}$. The ${ }^{1} \mathrm{H}$ NMR spectra of ligands HLa and HLb are shown in Figures 3 and 4, respectively.

In ${ }^{13} \mathrm{C}$ NMR spectra of HLa and HLb ligands, the azomethine carbon, $\mathrm{C}=\mathrm{N}$, was found to be at $159.12 \mathrm{ppm}$ and $153.24 \mathrm{ppm}$, respectively. As for $\mathrm{C}-\mathrm{OH}$, the signal appears downfield, at $163.25 \mathrm{ppm}$ and $162.46 \mathrm{ppm}$, respectively. The absence of thione carbon, $C=S$ peak in the spectra, in concordance to its absence in the FTIR spectra further convinced the microwave reaction of thiocarbohydrazide with salicylaldehyde derivatives, resulting in the formation of azine instead of thiocarbohydrazone.

3.3. Conventional Reflux vs. Microwave Irradiation. A comparison was made between conventional reflux used by previous literature [9] and the microwave irradiation method in synthesizing the HLa ligand and tabulated in Table 1. Previous work performed yields 15\% higher compared to current work. Despite the high yield, the process in obtaining the final product involves the two-step method that takes up to a total of 27 hours of reaction time, with the usage of ethanol and pyridine as solvents, in contrary to the microwave irradiation method which is able to complete the 
<smiles>[R3]c1ccc(O)c(/C=N\N=C\c2cc(Br)ccc2O)c1</smiles>

$$
\begin{gathered}
\text { R1 } \\
\text { HLa: }-\mathrm{H} \\
\text { HLb: }-\mathrm{OCH}_{3}
\end{gathered}
$$

Figure 1: General pathway of synthesizing HLa and HLb ligands.

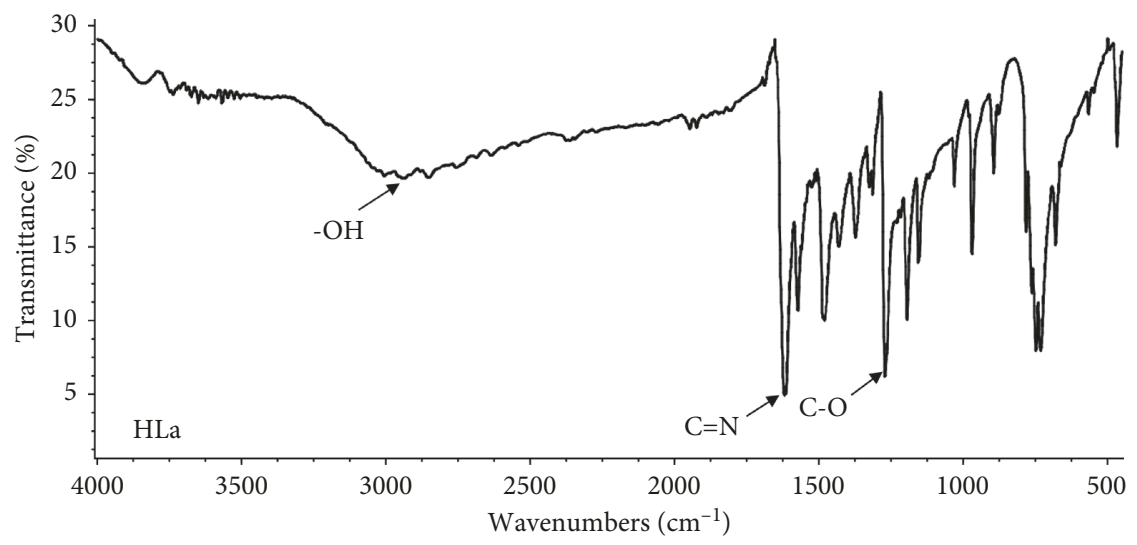

(a)

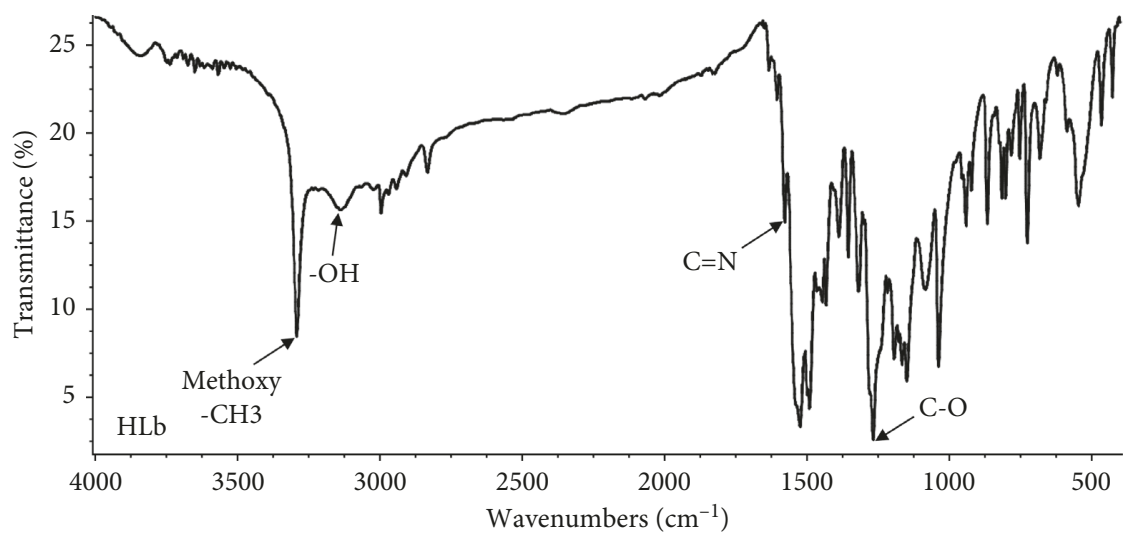

(b)

Figure 2: Infrared spectrum of (a) HLa and (b) HLb.

synthesis in 5 minutes (single-step method), using only ethanol as the solvent. The important ${ }^{1} \mathrm{H}$ NMR spectra of the important peaks also do not show any significant difference, thus maintaining and confirming the similarity of the structure HLa in both works.

The mass reduction in reaction time, number, and volume of solvent used in the microwave irradiation method while maintaining the purity not only improved the way of synthesizing HLa ligand but also minimized the cost and wastage in line with the Principle of Green Chemistry [12].

3.4. X-Ray Crystallography. Slow evaporation of ligand HLb in dichloromethane/ethanol mixture solvent gives needlelike crystal, which is suitable for X-ray crystallography analysis. The structure of HLb is illustrated in Figure 5, and the crystal data are tabulated in Table 2. 


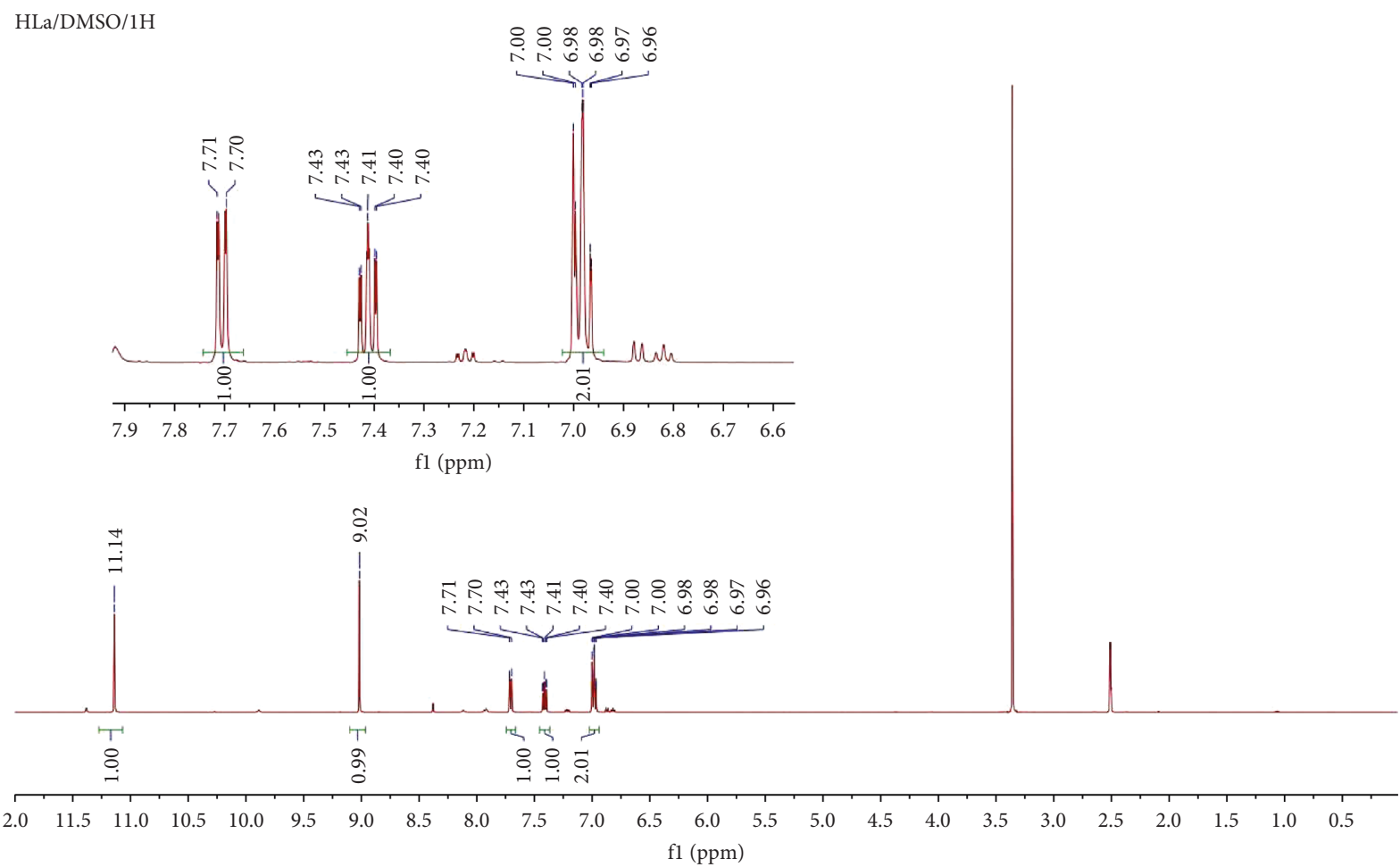

FIgURE 3: ${ }^{1} \mathrm{H}$ NMR spectrum of the ligand HLa.

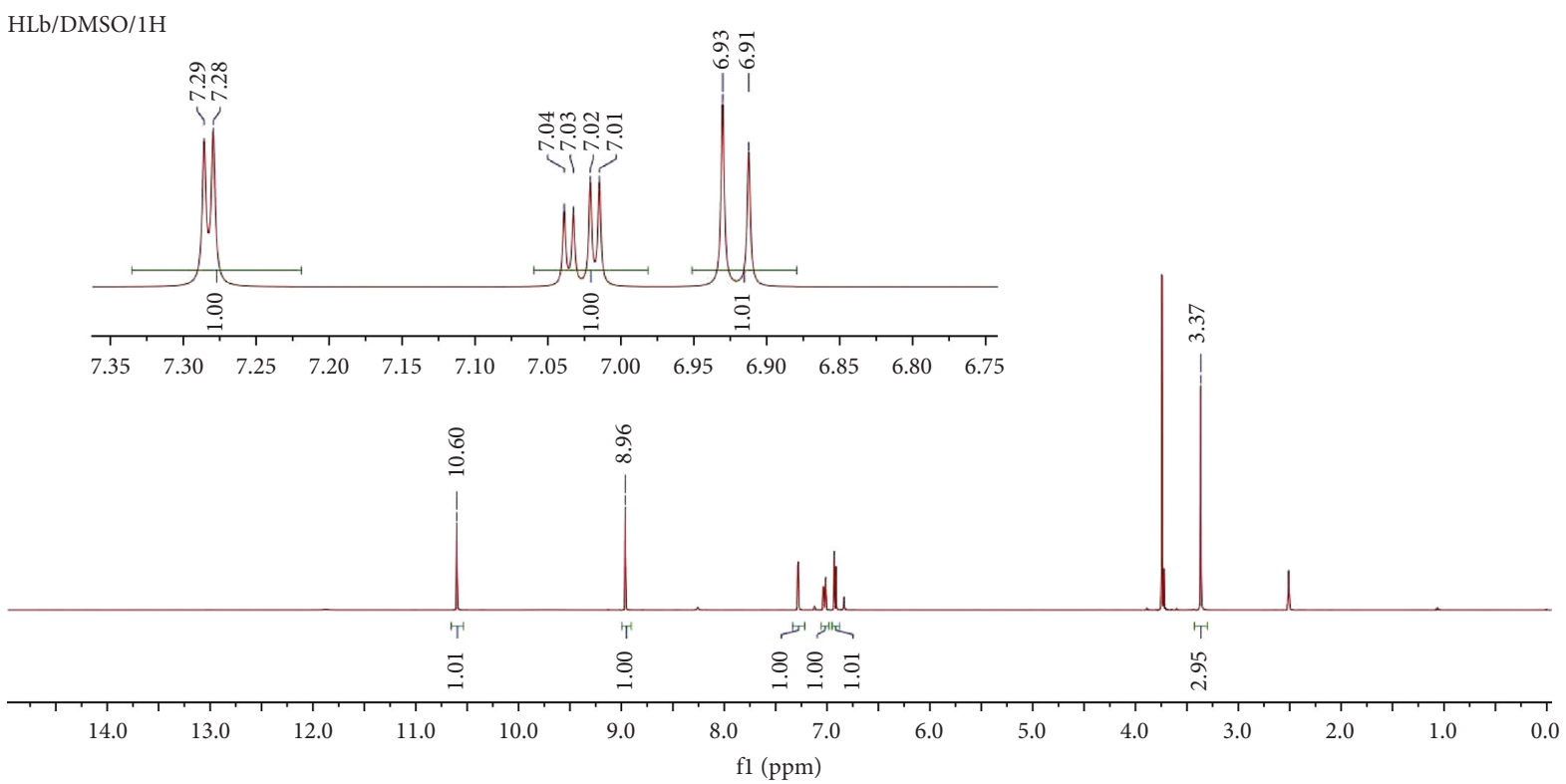

Figure 4: ${ }^{1} \mathrm{H}$ NMR spectrum of the ligand HLb.

The ligand HLb possessed a similar structure as reported by Randell et al. [13], with substituted methoxy group on the fifth benzene carbon. The inversion center about the N1-N1A bond adopts a centrosymmetric E,E configuration with respect to $\mathrm{C} 7=\mathrm{N} 1$ and the torsion angle of N1A-N1-C7-C1 = $179.3(2)^{\circ}$, conforming the presence of benzylidene as well as the imine bond formation. The whole molecule is essentially planar with the exception of the $\mathrm{C} 8$ and $\mathrm{C} 8 \mathrm{~A}$ atom with the maximum deviation of $0.113(3)^{\circ}$. The intramolecular hydrogen bond between N1-H1 ... O 1 and D-H... A distance of 142(3) A forms a stable six-membered hydrogen bound ring.

3.5. Antibacterial Study. Both azine ligands, HLa and HLb, were screened for antibacterial activity by the disc diffusion method, and the zone of inhibition is measured in millimeters, as tabulated in Table 3. A total of six bacterial strains were used to evaluate the biological properties of the ligands. 
TABLE 1: Comparison between conventional reflux and microwave irradiation in synthesizing HLa.

\begin{tabular}{lcc}
\hline & Conventional reflux & Microwave irradiation \\
\hline Yield (\%) & 97 & 82 \\
Total reaction time & 27 hours & 5 min \\
Solvent used & EtOH and pyridine & $80 \%$ EtOH \\
& $-\mathrm{OH}=11.10$ & $-\mathrm{OH}=11.14$ \\
${ }^{1} \mathrm{H}$ NMR peaks (ppm) & $\mathrm{HC}=\mathrm{N}=9.0$ & $\mathrm{HC}=\mathrm{N}=9.02$ \\
& $\mathrm{Ar}-\mathrm{H}=7.7-7.0$ & $\mathrm{Ar}-\mathrm{H}=7.71-6.96$ \\
\hline
\end{tabular}

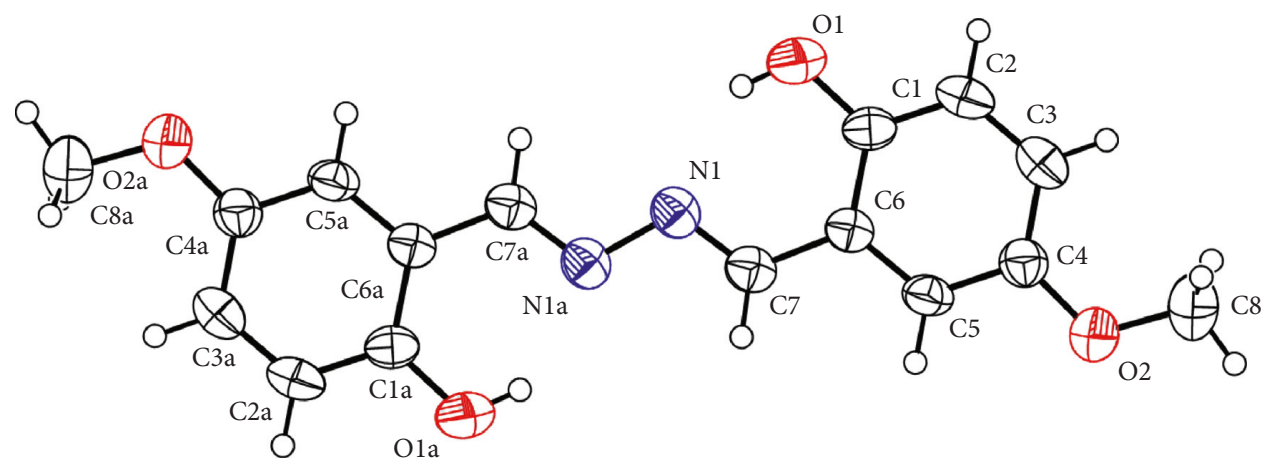

Figure 5: ORTEP view of ligand HLb. Thermal ellipsoids are shown at 50\% ellipsoid probability.

TABle 2: Crystal data of HLb.

Empirical formula

Formula weight

Temperature

Wavelength

Crystal system

Space group

Unit cell dimensions

Volume

Z

Density (calculated)

Absorption coefficient

Crystal size

Theta range for data collection

Reflections collected

Independent reflections

Completeness to theta $=25.242^{\circ}$

Refinement method

Data/restraints/parameters

Goodness-of-fit on $F^{2}$

Final $R$ indices $(I>2 \operatorname{sigma}(I))$

$R$ indices (all data)

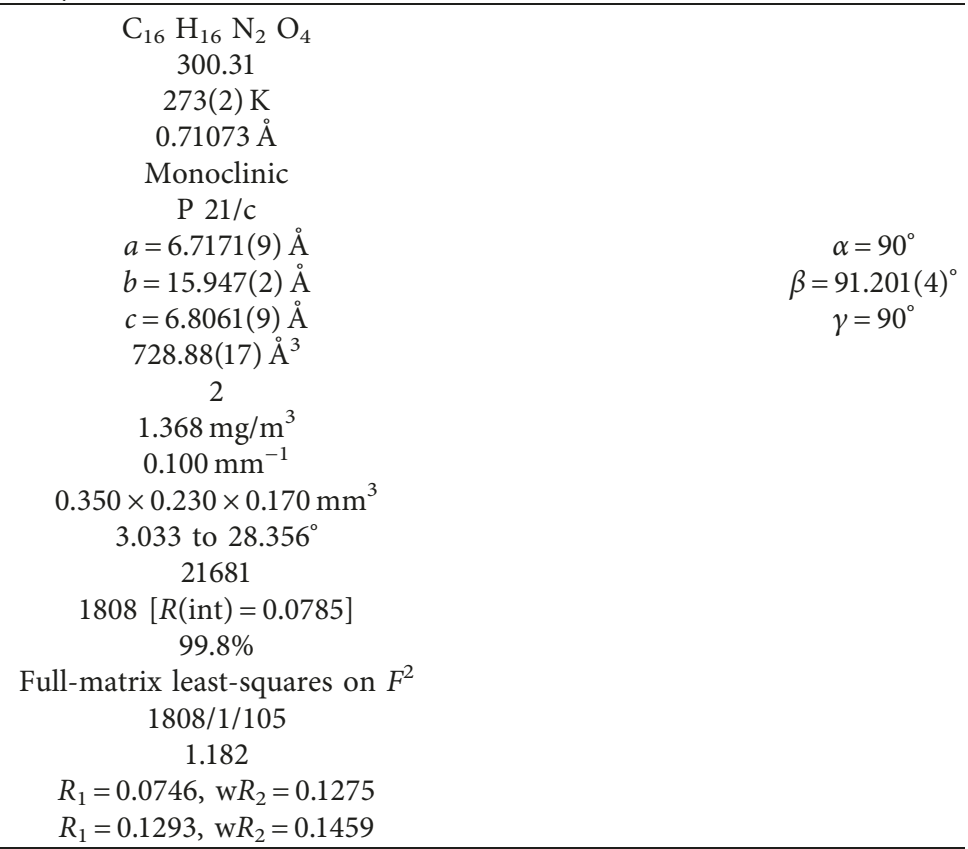

HLa is best used against $E$. coli, while HLb works great resisting the growth of $B$. subtilis. Overall, ligand HLb has more resistance towards all six bacterial strains compared to HLa although it is considered weak when compared to standard antibiotic, gentamicin. The substituent effect might be the reason for the enhancement of the biological properties of HLb. The electron-donating group (EDG), methoxy $\left(-\mathrm{CH}_{3}\right)$, donates electron to the $\pi$-system resulting a more nucleophilic $\pi$-system. The increases in nucleophilicity leads to the increases of lipophilicity of the compound as explained in Tweedy's theory $[14,15]$. The increased lipophilicity enhances the penetration of the compounds into the lipid membrane, thus enhancing its antimicrobial activities [16].

\section{Conclusion}

The usage of microware irradiation in synthesizing HLa and $\mathrm{HLb}$ resulted in the formation of azine ligand instead of thiocarbohydrazone. High energy from the microwave 
TABLE 3: Relative diameter of the inhibition zone exhibited by the ligands HLa and HLb.

\begin{tabular}{lccc}
\hline \multirow{2}{*}{ Strain } & \multicolumn{3}{c}{ Diameter of inhibition (mm) } \\
& HLa & HLb & Gentamicin \\
\hline B. cereus & - & 8 & 23 \\
B. subtilis & - & 9 & 23 \\
S. aureus & 8 & 7 & 25 \\
K. pneumoniae & 8 & 8 & 16 \\
P. aeruginosa & 8 & 8 & 23 \\
E. coli & 11 & 7 & 18 \\
\hline
\end{tabular}

irradiation causes the breakage of the thione, $\mathrm{C}=\mathrm{S}$ bond, enabling the amine to reattach to another amine terminal. As for the biological properties of the ligand, it was found that HLb possessed better resistance towards all six bacterial strains compared to HLa. This is due to the presence of the EDG substituent in HLb that enhanced the biological properties of the ligand.

\section{Data Availability}

The data used to support the findings of this study are available from the corresponding author upon request.

\section{Conflicts of Interest}

The authors declare that there are no conflicts of interest regarding the publication of this paper.

\section{Acknowledgments}

The authors gratefully acknowledge the Malaysian Ministry of Higher Education (MOHE) for providing research grant (600-RMI/FRGS 5/3 (0068/2016)) and the help of Universiti Teknologi MARA (UiTM) for providing the facilities to complete this research.

\section{Supplementary Materials}

CIF file of Ligand HLb. (Supplementary Materials)

\section{References}

[1] P. G. Cozzi, "Metal-Salen Schiff base complexes in catalysis: practical aspects," Chemical Society Reviews, vol. 33, no. 7, pp. 410-421, 2004.

[2] D. Chowrasia, C. Karthikeyan, L. Choure et al., "Synthesis, characterization and anti cancer activity of some fluorinated 3,6-diaryl-[1,2,4]triazolo[3,4-b][1,3,4]thiadiazoles," Arabian Journal of Chemistry, vol. 10, pp. S2424-S2428, 2017.

[3] R. D. Hunashal, P. M. Ronad, V. S. Maddi, D. Satyanarayana, and M. A. Kamadod, "Synthesis, anti-inflammatory and analgesic activity of 2-[4-(substituted benzylideneamino)-5(substituted phenoxymethyl)-4H-1,2,4-triazol-3-yl thio] acetic acid derivatives," Arabian Journal of Chemistry, vol. 7, no. 6, pp. 1070-1078, 2014.

[4] K. Parameswari, S. Chitra, A. Kiruthika, and A. Nagajothi, "Chelates of schiff bases derived from thiocarbohydrazide: synthesis and applications," Research Journal of Pharmaceutical, Biological and Chemical Sciences, vol. 4, no. 1, pp. 186-197, 2013.
[5] D. N. A. Chee, M. A. Affan, F. B. Ahmad et al., "Synthesis, characterization, and antibacterial activity of organotin(IV) complexes with 2-hydroxyacetophenone thiocarbohydrazone," Journal of Coordination Chemistry, vol. 64, no. 23, pp. 4191-4200, 2011.

[6] S. Caddick and R. Fitzmaurice, "Microwave enhanced synthesis," Tetrahedron, vol. 65, no. 17, pp. 3325-3355, 2009.

[7] C. P. Gharu, "Green and efficient microwave assisted synthesis of Schiff bases and hydroxyl derivatives of 1, 3, 4-thiadiazole containing $\mathrm{N}$-methyl piperazine moiety and their antimicrobial and antioxidant potential," Chemical Science Transactions, vol. 3, no. 4, pp. 1310-1317, 2014.

[8] K. Kassim and M. A. Hamali, "Green synthesis and antimicrobial studies of $\mathrm{Ni}(\mathrm{II})$ and $\mathrm{Zn}(\mathrm{II})$ dinuclear Schiff base complexes," International Journal of Engineering \& Technology, vol. 7, no. 3.11, p. 237, 2018.

[9] S. Lugasi, "New synthetic pathways for thiocarbohydrazide and salicylaldehyde azine compounds," Asian Journal of Chemical Sciences, vol. 3, no. 1, pp. 1-8, 2017.

[10] J. Hudzicki, Kirby-Bauer Disk Diffusion Susceptibility Test Protocol, 2009, http://scholar.google.com/scholar?hl=en\&btnG $=$ Search\&q=intitle:Kirby-Bauer+Disk + Diffusion+Susceptibility + Test+Protocol\#0.

[11] P. E. Aranha, M. P. dos Santos, S. Romera, and E. R. Dockal, "Synthesis, characterization, and spectroscopic studies of tetradentate Schiff base chromium(III) complexes," Polyhedron, vol. 26, no. 7, pp. 1373-1382, 2007.

[12] P. Anastas and N. Eghbali, "Green chemistry: principles and practice," Chemical Society Reviews, vol. 39, no. 1, pp. 301-312, 2010.

[13] N. M. Randell, L. K. Thompson, and L. N. Dawe, "6,6”Dimethoxy-2,2'-\{[(E,E)-hydrazine-1,2-diylidene $]$ bis(methanylylidene)\}diphenol methanol disolvate," Acta Crystallographica Section E Structure Reports Online, vol. 68, no. 9, article $02711,2012$.

[14] M. M. Abo-Aly, A. M. Salem, M. A. Sayed, and A. A. Abdel Aziz, "Spectroscopic and structural studies of the Schiff base 3-methoxy-N-salicylidene-o-amino phenol complexes with some transition metal ions and their antibacterial, antifungal activities," Spectrochimica Acta Part A: Molecular and Biomolecular Spectroscopy, vol. 136, pp. 993-1000, 2015.

[15] O. Taheri, M. Behzad, A. Ghaffari et al., "Synthesis, crystal structures and antibacterial studies of oxidovanadium(IV) complexes of Salen-type Schiff base ligands derived from meso-1,2-diphenyl-1,2-ethylenediamine," Transition Metal Chemistry, vol. 39, no. 2, pp. 253-259, 2014.

[16] M. Kalita, K. J. Tamuli, P. Barman, B. Sarma, R. Baruah, and H. P. Deka Boruah, "Synthesis, crystal structure, bioactivities of $\mathrm{Ni}(\mathrm{II}), \mathrm{Cu}(\mathrm{II}), \mathrm{Co}(\mathrm{II})$ and $\mathrm{Pd}(\mathrm{II})$ complexes with unsymmetrical thioether donor Schiff base: phosphine free Pd(II) complex catalyzed Suzuki reaction," Polyhedron, vol. 97, pp. 140-147, 2015. 

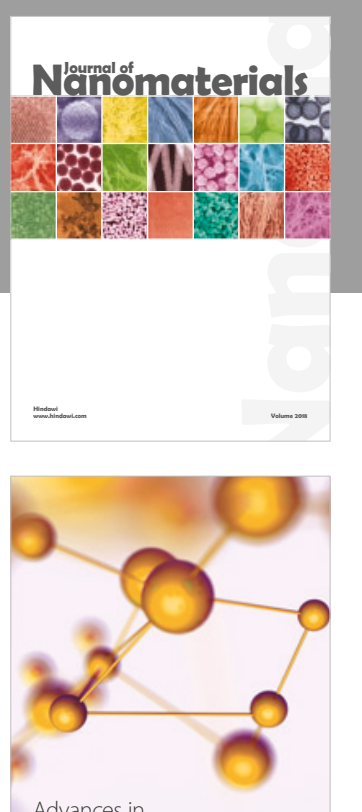

Physical Chemistry
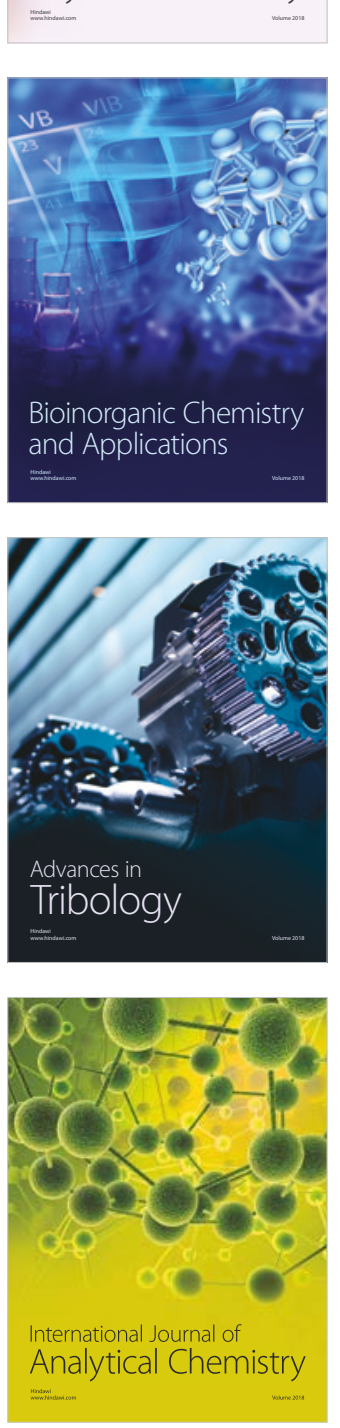

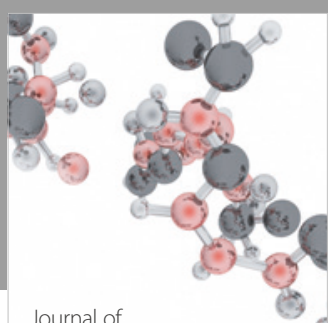

Analytical Methods

in Chemistry

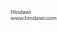

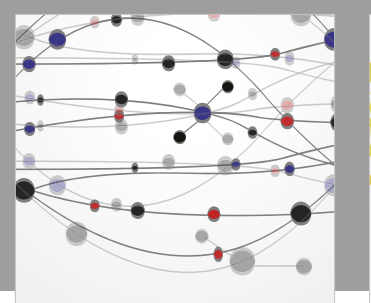

The Scientific World Journal

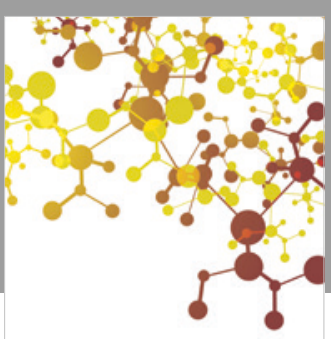

Journal of

Applied Chemistry
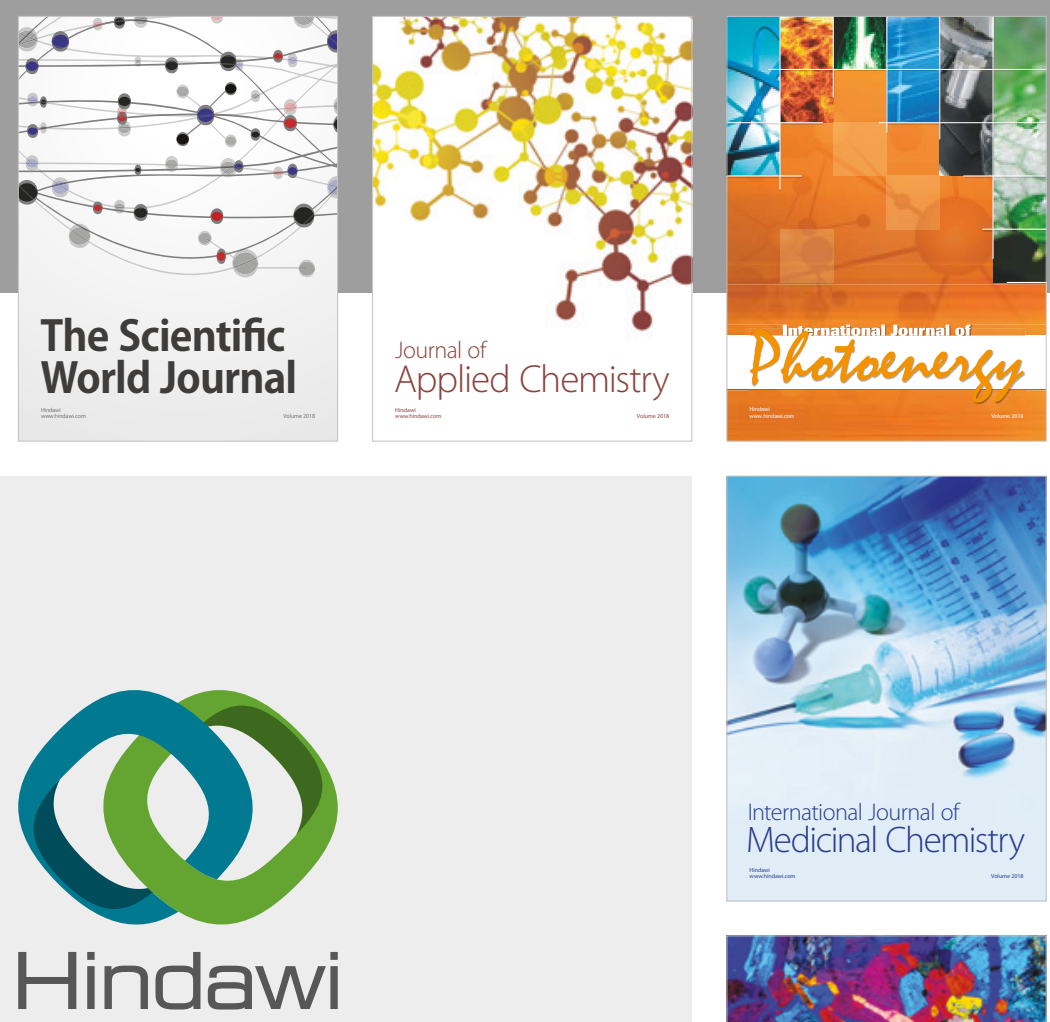

Submit your manuscripts at

www.hindawi.com
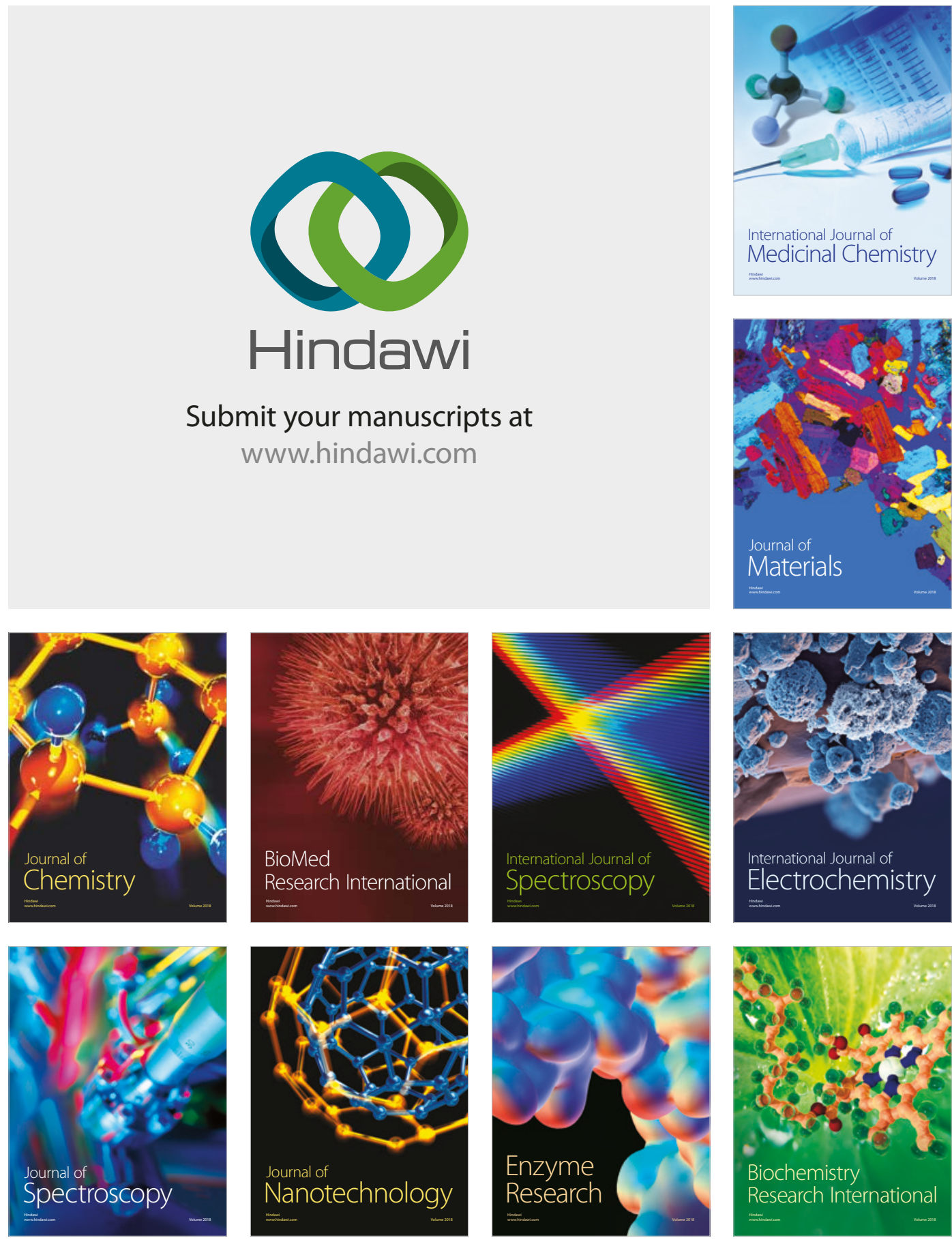
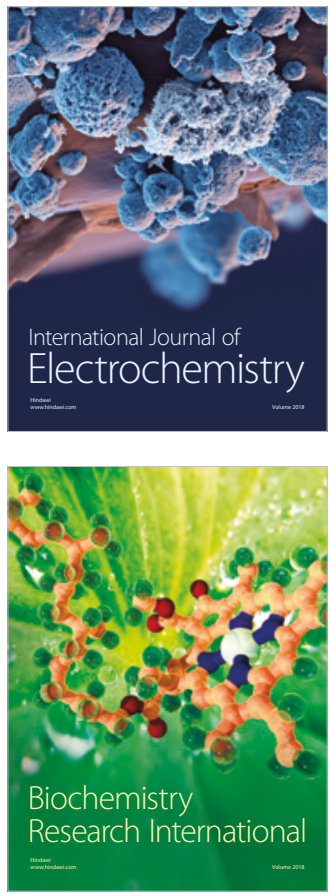